\title{
ANALISIS OPTIMALISASI MANAJEMEN PERSEDIAAN PADA BAHAN BAKU BIJIH PLASTIK (DI PT. NISSEN CHEMITEC INDONESIA)
}

\author{
N. Neni Triana1, Riza Muztaba², Muhamad Sayuti' ${ }^{3}$, Afif Hakim ${ }^{4}$ \\ ${ }^{1}$ Jurusan Teknik Industri, Fakultas Teknik dan Ilmu Komputer, Universitas Buana Perjuangan Karawang \\ Jl. HS. Ronggowaluyo Telukjambe Timur Karawang, \\ ${ }^{2}$ Jurusan Teknik Industri, Fakultas Teknik dan Ilmu Komputer, Universitas Buana Perjuangan Karawang \\ Jl. HS. Ronggowaluyo Telukjambe Timur Karawang \\ ${ }^{3}$ Jurusan Teknik Industri, Fakultas Teknik dan Ilmu Komputer, Universitas Buana Perjuangan Karawang \\ ${ }^{4}$ Jurusan Teknik Industri, Fakultas Teknik dan Ilmu Komputer, Universitas Buana Perjuangan Karawang \\ Jl. HS. Ronggowaluyo Telukjambe Timur Karawang \\ Email: neni.triana@ubpkarawang.ac.id
}

\begin{abstract}
Material inventory as a very important thing for every company. Manufacturing companies generally have inventory to be able to provide the best service to customers. The purpose of this study is to try to achieve the minimum inventory levels possible, reduce storage costs, maximize material storage space for materials fast moving. The author uses ABC Analysis to determine the plastic ore material that is fast moving and is in class A. Then proceed with forecasting the needs of plastic ore raw materials for 2019. The Economic Order Quantity (EOQ) method is used in this study after knowing the material in class $A$ with a percentage value of $64.20 \%$ of material requirements and to determine the quantity of inventory orders that minimize the direct cost of storing inventory, ordering costs and optimizing the frequency of ordering materials. This research is useful for companies by minimizing direct costs of inventory storage, ordering costs and optimizing the frequency of ordering materials. PT. Nissen Chemitec Indonesia usually orders material in 1 year, 12 times material orders, which means that every month the company will order materials. In this analysis, forecasting of material needs is carried out for September 2019 to December 2019 because from the January to August period the company has purchased material. Material purchase with a lead time of 14 days for all types of material. Before using the EOQ method, the total inventory cost of raw materials is Rp. 2,286,376.58 and the company does not have a safety stock. If using the EOQ method the total inventory cost of raw materials is Rp. 812,009 with a frequency of ordering 1 time in 4 months period. The safety stock is 1,095 $\mathrm{kg}$, and the reorder point is if the raw material is at the amount of 2,618 $\mathrm{kg}$. This research is expected to minimize procurement costs and optimize the number of purchases that can be used at PT. Nissen Chemitec Indonesia so that all raw material procurement processes can be better for the company.
\end{abstract}

Keywords: Analysis; Inventory Managemen; ABC Analysis; EOQ Method.

\begin{abstract}
ABSTRAK
Persediaan material sebagai hal yang sangat penting bagi setiap perusahaan. Perusahaan manufaktur umumnya memiliki persediaan agar mampu memberikan pelayanan yang terbaik pada pelanggan. Tujuan penelitian ini adalah berusaha mencapai tingkat persediaan seminimum mungkin, mengurangi biaya penyimpanan, memaksimalkan ruang penyimpanan material untuk fast moving material. Penulis menggunakan ABC Analysis untuk mengetahui fast moving material bijih plastik dan berada di kelas A. Kemudian di lanjutkan dengan melakukan peramalan kebutuhan bahan baku bijih plastik untuk tahun 2019. Metode Economic Order Quantity (EOQ) digunakan pada penelitian ini setelah mengetahui material yang berada di kelas A dengan nilai persentase yaitu 64,20\% dari kebutuhan material dan untuk menentukan kuantitas pesanan persediaan yang meminimumkan biaya langsung penyimpanan persediaan, biaya pemesananan (ordering cost) dan mengoptimalkan frekuensi pemesanan material. Penelitian ini bermanfaat bagi perusahaan dengan meminimumkan biaya langsung penyimpanan persediaan, biaya pemesananan (ordering cost) dan mengoptimalkan frekuensi pemesanan material. Kebijakan PT. Nissen Chemitec Indonesia biasa melakukan order material dalam 1 tahun adalah 12 kali order material yang artinya setiap satu bulan perusahaan akan melakukan order material. Pada analisis ini peramalan kebutuhan material di lakukan untuk bulan September 2019 sampai dengan Desember 2019 karena Dari periode bulan Januari sampai dengan Agustus pihak perusahaan telah melakukan pembelian material. Pembelian material dengan lead time 14 hari untuk
\end{abstract}


seтиa jenis material. Sebelum mengunakan metode EOQ Total biaya persediaan bahan baku perusahaan sebesar Rp. 2.286.376,58 dan perusahaan tidak mempunyai persediaan pengaman. Apabila menggunakan metode EOQ total biaya persediaan bahan baku adalah Rp. 812.009 dengan frekuensi pemesanan $1 \mathrm{kali}$ dalam 4 bulan periode. Persediaan pengaman sebesar $1.095 \mathrm{Kg}$, dan titik pemesanan kembali apabila bahan baku berada pada tingkat jumlah $2.618 \mathrm{Kg}$. Penelitian ini di harapkan bermanfaat mampu meminimumkan biaya persediaan material dan mengoptimalkan frekuensi pembelian persediaan yang di gunakan di PT. Nissen Chemitec Indonesia agar semua proses pengadaan bahan baku dapat lebih baik bagi perusahaan.

Kata Kunci: Analisis: Manajemen Persediaan; ABC Analysis; Metode EOQ.

\section{PENDAHULUAN}

Persediaan sebagai hal yang sangat penting bagi perusahaan. Persediaan dapat terdiri dari persediaan bahan baku, barang dalam proses (WIP), bahan pembantu, barang jadi. Perusahaan manufaktur umumnya memiliki persediaan agar mampu memberikan pelayanan yang terbaik pada pelanggan. Sebuah perusahaan yang baik harus dapat memiliki stock persediaan yang cukup untuk melakukan proses produksi dengan lancar, tidak ada keterlambatan serta yang terpenting adalah dapat memenuhi permintaan customer. Keterlambatan bisa berakibat fatal bagi perusahaan, tidak hanya menyebabkan terhambatnya atau bahkan terhentinya produksi, namun lebih dari itu bisa menyebabkan kehilangan kesempatan untuk meningkatkan produksi dan penjualan, sehingga juga menyebabkan hilangnya kesempatan untuk meningkatkan keuntungan perusahaan. Faktor yang terkait dengan persediaan untuk melaksanakan pengendalian persediaan harus diperhatikan. Faktor tersebut yaitu perkiraan, harga bahan baku, pemakaian bahan baku, biaya persediaan dan waktu menunggu pemesanan. Setiap perusahaan memiliki kebijakan persediaan bahan baku yang diterapkan dalam perusahaannya, biaya persediaan dan biaya bahan baku tersebut dapat ditekan sekecil mungkin, untuk meminimumkan biaya persediaan tersebut dapat menggunakan ABC Analysis, kemudian di lanjutkan dengan metode EOQ (Economic Order Quantity). PT. Nissen Chemitec Indonesia merupakan perusahaan yang bergerak dibidang Manufaktur injection plastic, yang kegiatan utamanya adalah memproduksi sparepart kendaraan roda empat. Bahan baku yang digunakan dalam proses produksi adalah bijih plastik. Pelaksanaan proses produksinya bahan baku tersebut selalu tersedia dan merupakan barang yang paling penting (fast moving) untuk kelancaran proses produksi. Perusahaan biasa melakukan order material dalam 1 tahun adalah 12 kali order material yang artinya setiap satu bulan perusahaan akan melakukan order material, padahal untuk forecast produksi dengan menggunakan material tersebut sudah ada untuk satu tahun kedepan. Pemesanan kembali (Re-Order Point) bisa lebih di optimalkan dengan melihat kebutuhan bahan baku satu tahun kedepan. Oleh sebab itu perlu dilaksanakan perencanaan dan pengendalian bahan baku yang lebih efisien dengan mengurangi frekuesi order material, maka dilakukan $\mathrm{ABC}$ Analysis untuk melihat kelas dari setiap material yang di gunakan dalam proses produksi, menghitung peramalan material yang di butuhkan untuk tahun 2019, kemudian melakukan optimalisasi bahan baku dengan metode EOQ sebagai salah satu pilihan perbandingan antara kebijakan yang telah dilaksanakan dengan metode EOQ, sehingga perusahaan dapat memilih kebijakan mana yang lebih efisien dalam hal pengeluaran biaya persediaan atau total biaya persediaan. Sistem persediaan sebagai serangkaian kebijakan dan pengendalian yang memantau dan memonitor jumlah dan tingkat persediaan agar bisa menentukan tingkat persediaan yang harus dijaga. Menurut Assauri dalam jurnal Gema dan Retno (2014) manajemen persediaan dapat dikatakan sebagai suatu kegiatan untuk mengontrol jumlah persediaan bahan baku dan persediaan barang jadi, maka perusahaan dapat menghindari tergangunya proses produksi dan mengetahui penjualan dan pembeliaan yang optimal. ABC analysis yang merupakan penerapan persediaan dari prinsip Pareto. Prinsip Pareto menyatakan ada beberapa yang penting dan tidak. Untuk menentukan volume harga tahunan $\mathrm{ABC}$ analysis, permintaan tahunan dari setiap barang persediaan dihitung dan dikalikan dengan harga per unit. $\mathrm{ABC}$ analysis membagi persediaan menjadi tiga kelompok berdasarkan volume tahunan dalam jumlah harga setiap materialnya. Menurut Prasetyawan dan Nasution dalam jurnal Jandu Setiawan (2010) kebijakan yang dapat didasarkan pada ABC analysis mencakup hal-hal sebagai berikut :

1. Pembelian sumber daya yang dibelanjakan pada pengembangan pemasok harus jauh lebih tinggi untuk barang A dibandingkan barang $\mathrm{C}$. 
2. Barang A tidak seperti barang $B$ dan $C$, perlu memiliki pengendalian persediaan fisik yang lebih ketat, mungkin mereka dapat diletakkan pada tempat yang lebih aman, dan mungkin akurasi catatan pesediaan untuk barang A lebih sering diverifikasi.

3. Prediksi barang A perlu lebih dijamin keabsahannya dibanding dengan prediksi barang B dan C.

Pareto mengklasifikasikan barang-barang dalam analisis persediaan $\mathrm{ABC}$ dengan kriteria umum sebagai berikut :

a. Kelas A = Barang dengan jumlah unit $10-25 \%$ tetapi nilai investasinya 30-70\% dari total investasi tahunan persediaan

b. Kelas B = Barang dengan jumlah unit 20-30\% tetapi nilai investasinya 20-30\% dari total investasi tahunan persediaan

c. Kelas $\mathrm{C}=$ Barang dengan jumlah unit $30-70 \%$ tetapi nilai investasinya $10-20 \%$ dari total investasi tahunan persediaan

Adapun langkah-langkah yang dilakukan dalam $\mathrm{ABC}$ analysis adalah :

1. Menentukan volume tahunan dalam nilai uang (Volume tahun (dalam unit) $\mathrm{x}$ harga per unit

2. Susun item persediaan berdasarkan volume tahunan rupiah dari yang terbesar.

3. Jumlah presentasi tahunan rupiah secara komulatif.

4. Menentukan presentasi komulatif

\section{Linear Regresi}

Regresi dalam pengertian moderen menurut Gujarati (2018) "ialah sebagai kajian terhadap ketergantungan satu variabel, yaitu variabel tergantung terhadap satu atau lebih variabel lainnya atau yang disebut sebagai variabel - variabel eksplanatori dengan tujuan untuk membuat estimasi dan atau memprediksi rata - rata populasi atau nilai rata-rata variabel tergantung dalam kaitannya dengan nilai - nilai yang sudah diketahui dari variabel ekslanatorinya". Analisis regresi berkaitan dengan ketergantungan atau dependensi satu variabel terhadap variabel - variabel lainnya hal tersebut tidak harus menyiratkan sebab - akibat (causation).

Model Persamaan Regresi Linear sebagai berikut :

Dimana :

$$
\mathbf{Y}=\mathbf{a}+\mathbf{b X}
$$

$\mathrm{Y}=$ Variabel Response atau Variabel Akibat (Dependent)

$\mathrm{X}=$ Variabel Predictor atau Variabel Faktor Penyebab (Independent)

$\mathrm{a}=$ konstanta

$\mathrm{b}=$ koefisien regresi (kemiringan); besaran Response yang ditimbulkan oleh Predictor. Nilai-nilai a dan $b$ dapat dihitung dengan menggunakan Rumus dibawah ini :

$$
\begin{array}{r}
\mathbf{a}=\frac{(\Sigma \mathbf{V})\left(\Sigma \mathbf{X}^{2}\right)-(\Sigma \mathbf{X})(\Sigma \mathbf{X V})}{\mathbf{n}\left(\Sigma_{\mathbf{X}}\right)-(\Sigma \mathbf{X})^{2}} \\
\mathbf{b}=\frac{\mathbf{n}(\Sigma \mathbf{X V})-(\Sigma \mathbf{X})\left(\Sigma_{\mathbf{V}}\right)}{\mathbf{n}\left(\Sigma^{2}\right)-(\Sigma \mathbf{X})^{2}}
\end{array}
$$

\section{METODE PENELITIAN}

Objek penelitian adalah PT. Nissen Chemitec Indonesia, dan data yang digunakan data sekunder yang didapatkan dari Departemen PPIC (Production Planning and Inventory Control) perusahaan. Adapun langkah-langkah dari penelitian dimulai dari identifikasi masalah dan tujuan, kemudian pengumpulan data menggunakan wawancara dengan Leader dan Supervisor bagian PPIC, dan observasi secara langsung. Penelitian Afianti, H.F dan Azwir, H. H (2016), menyatakan bahwa ABC (Analysis Based Costing System) dapat mengurangi risiko shortage sebanyak 26\%, overstock sebesar 12\%, dan secara total keseluruhan over value inventory dapat diturunkan sebanyak 23\%. ABC System dapat mengklasifikasikan material prioritas sehingga dapat menjadi dasar dalam penghitungan EOQ. Menurut Amrillah, A.F., etc (2016), penerapan metode Economic Order Quantity dapat menentukan kuantitas pembelian bahan baku secara optimal, juga meminimalkan total biaya yang dikeluarkan oleh perusahaan setiap tahunnya. Data semua bahan baku yang di gunakan dalam proses produksi di hitung menggunakan ABC Analysis, melakukan peramalan bahan baku September sampai dengan Desember 2019, menghitung total persediaan dengan kebijakan perusahaan serta penghitungan dengan metode EOQ. Menurut Assauri dalam jurnal Gema dan Retno (2014) manajemen persediaan dapat dikatakan 
sebagai suatu kegiatan untuk mengontrol jumlah persediaan bahan baku dan persediaan barang jadi, maka perusahaan dapat menghindari tergangunya proses produksi dan mengetahui penjualan dan pembeliaan yang optimal. Metode Economic Order Quantity

Menurut Handoko dalam jurnal Safa'at (2017) Metode Economic Order Quantity (EOQ) dapat digunakan baik untuk barang-barang yang dibeli maupun yang diproduksi sendiri. Metode EOQ adalah nama yang biasa digunakan untuk barang-barang yang dibeli, sedangkan ELS (economic lot size) digunakan untuk barang-barang yang diproduksi secara internal. Perbedaan pokoknya adalah bahwa untuk ELS biaya pemesanan (ordering cost) meliputi biaya penyiapan pesanan untuk dikirim ke pabrik dan biaya penyiapan mesin-mesin (setup cost) yang diperlukan untuk mengerjakan pesanan.

Rumus EOQ yang biasa digunakan adalah :

$$
\mathrm{EOQ}=\sqrt{\frac{2 D S}{H}}
$$

Dimana :

$\mathrm{D}=$ Penggunaan atau permintaan yang diperkirakan per periode waktu

$\mathrm{S}=$ Biaya pemesanan

$\mathrm{H}=$ Biaya penyimpanan per unit per tahun

Titik Pemesanan Ulang (Re Order Point) Berikut adalah rumus Re-Order Point :

$$
\text { ROP }=(\text { d.L })+\text { Safety Stock }
$$

Dimana penjelasan tersebut adalah antara lain sebagai berikut :

1. $\quad \mathrm{D}=$ Pemakaian bahan baku.

2. $\quad \mathrm{L}=$ Lead time atau waktu tunggu.

3. $\mathrm{SS}=$ Safety stock adalah persediaan pengaman.

Persediaan Pengaman (Safety Stock), Berikut adalah rumus safety stock:

$$
\mathrm{SD}=\sqrt{\frac{\sum(X-\bar{X})^{2}}{n}}
$$

Keterangan :

1. $\mathrm{X}=$ Kebutuhan Bahan Baku

2. $\bar{X}=$ Rata-rata Kebutuhan Bahan Baku

3. $n=$ Periode pemesanan

Dimana:

$$
\text { Safety Stock }=\text { Z (tabel) } \times \text { SD }(\text { Standar Deviasi) }
$$

$1 . \mathrm{Z}=$ Nilai $\mathrm{Z}$ tabel

2. $\mathrm{SD}=$ Hasil dari Standar Deviasi

\section{HASIL DAN PEMBAHASAN}

\section{Peramalan Bahan Baku}

PT. Nissen Chemitec Indonesia melakukan pengadaan bahan baku bijih plastik dengan kode HN-10 NH-167L dengan melakukan pemesanan sebulan sekali sehingga terjadi 12 kali pemesanan dalam 
satu tahun. Pemesanan di lakukan kepada supplier yaitu PT. Honda Trading Indonesia. Berikut adalah data kebutuhan bahan baku HN-10 NH-167L pada tahun 2018.

Tabel 6. Kebutuhan Bahan Baku Tahun 2018

\begin{tabular}{ccc}
\hline Month & QTY & Unit \\
\hline Jan-18 & 15.000 & $\mathrm{Kg}$ \\
\hline Feb-18 & 35.000 & $\mathrm{Kg}$ \\
\hline Mar-18 & 33.200 & $\mathrm{Kg}$ \\
\hline Apr-18 & 45.000 & $\mathrm{Kg}$ \\
\hline Mei-18 & 41.000 & $\mathrm{Kg}$ \\
\hline Jun-18 & 34.000 & $\mathrm{Kg}$ \\
\hline Jul-18 & 53.000 & $\mathrm{Kg}$ \\
\hline Agu-18 & 62.000 & $\mathrm{Kg}$ \\
\hline Sep-18 & 68.000 & $\mathrm{Kg}$ \\
\hline Okt-18 & 85.000 & $\mathrm{Kg}$ \\
\hline Nov-18 & 71.000 & $\mathrm{Kg}$ \\
\hline Des-18 & 33.000 & $\mathrm{Kg}$ \\
\hline & & $\mathbf{5 7 5 . 2 0 0}$ \\
\hline
\end{tabular}

\section{Sumber : Data Perusahaan PT. NCI 2018}

Terlihat pada tabel 6 kebutuhan bahan baku berbeda-beda tiap bulannya selama satu tahun. Terjadi peningkatan kebutuhan bahan baku HN-10 NH-167L yang lebih tinggi pada bulan oktober 2018 yaitu sebesar $85.000 \mathrm{~kg}$. Hal ini di sebabkan karena mendekati akhir tahun dan biasanya produksi mobil dan motor lebih tinggi dari bulan-bulan lainnya. Lebih jelasnya dapat di lihat pada grafik berikut ini.

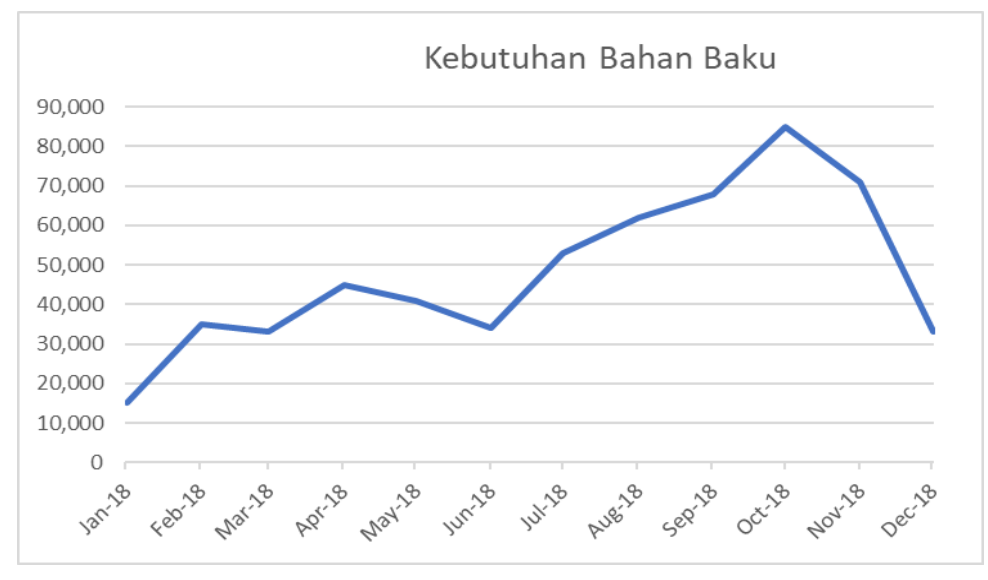

\section{Peramalan Kebutuhan Bahan Baku}

Setelah melakukan langkah-langkah $\mathrm{ABC}$ analysis di ketahui bahwa material yang masuk kedalam kelas A yang harus dilakukan pengendalian yang optimal adalah material HN-10 NH-167L. Maka di lakukan peramalan kebutuhan bahan baku pada tahun 2019 dengan menggunakan Linear Regresi. Hasil peramalan permintaan dengan metode Regresi Linier untuk tahun 2019 dapat di lihat pada tabel 7. 
Tabel 7. Peramalan bahan baku material HN-10 NH 167 L tahun 2019

\begin{tabular}{|l|l|c|}
\cline { 2 - 3 } \multicolumn{1}{|c|}{ Bulan } & Kebutuhan bahan baku (Kg) \\
\cline { 2 - 3 } Berikut & September & 46751,09 \\
\hline \multirow{4}{*}{ Odalah } & Oktober & 46751,16 \\
\cline { 2 - 3 } & November & 46751,22 \\
\cline { 2 - 3 } & Desember & 46751,29 \\
\cline { 2 - 3 } & Total & $\mathbf{1 8 7 . 0 0 5}$ \\
\hline
\end{tabular}

Sumber : Data

PT. NCI yang

di olah

rincian biaya

dapat di liat pada

tabel 8 .

Tabel 8. Biaya Pemesanan

\begin{tabular}{|c|l|r|}
\hline No & & Price \\
\hline 1 & Biaya Karyawan & 4.550 .000 \\
\hline 2 & Biaya Administrasi & 1.000 .000 \\
\hline 3 & Biaya Telepon & 500.000 \\
\hline & Jumlah & $\mathbf{6 . 0 5 0 . 0 0 0}$ \\
\hline
\end{tabular}

Sumber : Data PT. NCI yang di olah

\section{Perhitungan Biaya Pesan dan Biaya Simpan}

Biaya Pemesanan setap kali pesan (s)

$$
=\frac{\text { Total Biaya Pesan }}{\text { Frekuesi Pemesanan }}=\frac{R p \text { 6.050.000,- }}{12}=\text { Rp. 504.166.- }
$$

\section{Biaya penyimpanan persatuan bahan baku $(\mathrm{H})$}

$$
=\frac{\text { Total Biaya Simpan }}{\text { Total Kebutuhan Bahan Baku }}=\frac{R p 6.490 .000,-}{561.005 \mathrm{Kg}}=\mathrm{Rp} .11,56,-/ \mathrm{Kg}
$$

\section{Kebijakan Perusahaan}

Pembelian bahan baku (Q) dapat dihitung berdasarkan kebijakan perusahaan yang melakukan pemesanan setiap bulan sekali, maka dapat diketahui sebagai berikut :

$$
=\frac{\text { Total Biaya Bahan Baku }}{\text { Frekuensi pemesanan }}=\frac{187.005 \mathrm{Kg}}{4}=46.761,25=46.761 \mathrm{Kg}
$$

Jadi besarnya jumlah pembelian bahan baku pada PT. Nissen Chemitec Indonesia dalam sekali pemesanan adalah sebesar $46.761 \mathrm{Kg}$.

\section{Total Biaya Persediaan}

Agar dapat menghitung biaya persediaan yang di perlukan oleh PT. NCI maka diketahui :

- Total Kebutuhan Bahan Baku (D) =

- Pembelian rata-rata bahan baku $(\mathrm{Q}) \quad=\quad 46.761 \mathrm{Kg}$

- Biaya pemesanan sekali pesan $(\mathrm{S}) \quad=\quad$ Rp. 504.166.-

- Biaya simpan per $\mathrm{Kg}(\mathrm{H}) \quad$ = $\quad$ Rp. $11,56,-/ \mathrm{Kg}$ 
Total Biaya Persediaan (TIC) sebagai berikut :

$$
\begin{aligned}
\text { TIC } & =\left[\frac{D}{Q} S\right]+\left[\frac{Q}{2} H\right] \\
& =\left[\frac{187.005 \mathrm{Kg}}{46.761} R p 504.166,\right]+\left[\frac{46761}{2} R p 11,56,\right] \\
& =\text { Rp. } 2.016 .043,55+\text { Rp. } 270.278,58 \\
& =\text { Rp. } 2.286 .376,58
\end{aligned}
$$

Jadi Total biaya persediaan yang harus di tanggung oleh PT. Nissen Chemitec Indonesia adalah Rp. 2.286.376,58

Pembelian bahan baku yang ekonomis ini dapat di lihat berdasarkan pada:

- Total Kebutuhan Bahan Baku (D) $=187.005 \mathrm{Kg}$

- Pembelian rata-rata bahan baku $(\mathrm{Q})=\quad 46.761 \mathrm{Kg}$

- Biaya pemesanan sekali pesan $(\mathrm{S})=$ Rp. 504.166.-

- Biaya simpan per $\mathrm{Kg}(\mathrm{H}) \quad=\quad \mathrm{Rp} .11,56,-/ \mathrm{Kg}$

Besarnya pembelian bahan baku yang ekonomis menggunakan metode EOQ adalah sebagai berikut:

$$
Q=\sqrt{\frac{2 D S}{H}}=\sqrt{\frac{2 \times 187.005 \times R p 504.166,-}{R p 11,56-}}=127.606,9 \mathrm{Kg}=127.607 \mathrm{Kg} .
$$

Jadi jumlah pembelian bahan baku yang ekonomis dengan menggunakan metode EOQ adalah sebesar $127.607 \mathrm{Kg}$.

\section{Frekuensi Pemesanan Bahan Baku}

Menggunakan metode EOQ dapat di hitung jumlah frekuensi pemesanan dalam satu tahun sebagai berikut :

$$
\begin{aligned}
& F=\sqrt{\frac{D}{Q}} \\
& F=\sqrt{\frac{187.005}{127.607}} \\
& F=1,21=1 \text { kalí }
\end{aligned}
$$

Jadi frekuensi pemesanan bahan baku menurut metode EOQ adalah 1 kali dalam setahun.

\section{Total Biaya Persediaan}

Diketahui :

1. Total biaya kebutuhan bahan baku (D) $=187.005 \mathrm{Kg}$

2. Biaya pemesanan sekali pesan $(\mathrm{S}) \quad=\mathrm{Rp}$. 504.166.-

3. Biaya Simpan per $\mathrm{Kg}(\mathrm{H}) \quad=$ Rp. $11,56,-/ \mathrm{Kg}$ 
4. Pembelian bahan baku yang ekonomis $\left(\mathrm{Q}^{*}\right) \quad=127.607 \mathrm{Kg}$

$$
\mathrm{TIC}=\left[\frac{D}{Q^{*}} S\right]+\left[\frac{Q^{*}}{2} H\right]
$$

$\mathrm{TIC}=\left[\frac{187.005}{127.607} R p 504.166,-\right]+\left[\frac{127.607}{2} R p 11,56\right]$

$\mathrm{TIC}=$ Rp. $738.603+$ Rp. 734,06

TIC $=$ Rp. 812.009

Jadi Total Biaya Persediaan bahan baku PT Nissen Chemitec Indonesia bila menggunakan metode EOQ sebesar Rp. 812.009.

\section{Persediaan Pengaman}

Tabel 9. Standar Deviasi

\begin{tabular}{|l|c|c|c|c|}
\hline \multicolumn{1}{|c|}{ Month } & Kebutuhan bahan baku & ${ }^{-} X$ & $\left(X-{ }^{-} X\right.$ & $\left(X-X^{2}\right.$ \\
\hline September & 46751,09 & 46751,2 & $-0,11$ & 0,0121 \\
\hline Oktober & 46751,16 & 46751,2 & $-0,04$ & 0,0016 \\
\hline November & 46751,22 & 46751,2 & 0,02 & 0,0004 \\
\hline Desember & 46751,29 & 46751,2 & 0,09 & 0,0081 \\
\hline \multicolumn{4}{|c|}{ Jumlah } & 0,0222 \\
\hline
\end{tabular}

Sumber : Data PT. NCI yang diolah.

$$
\mathrm{SD}=\sqrt{\frac{0,0222}{4}}=\quad \mathrm{SD}=\sqrt{\frac{\sum(X-\bar{X})^{2}}{n}} \quad 0,74
$$

Asumsi atau perkiraan perusahaan memenuhi permintaan sebesar $93 \%$ dan persediaan cadangan sebesar 7\% maka di peroleh $\mathrm{Z}$ tabel normal dengan nilai 1,48 dari deviasi standar dari rata-rata.

Safety Stock $\mathrm{Z} \quad=\quad \mathrm{Z} \times \mathrm{SD}$

$$
\begin{array}{ll}
= & 1,48 \times 0,74 \\
= & 1,095 \mathrm{Kg}
\end{array}
$$

Jadi persediaan pengaman yang harus disediakan oleh perusahaan adalah sebesar $1095 \mathrm{Kg}$.

\section{Titik Pemesanan Kembali ( Re-Order Point )}

PT. Nissen Chemitec Indonesia memiliki lead time (L) pemesanan bahan baku HN-10 NH167L yaitu selama 14 hari. Dan dengan jumlah rata-rata kerja dalam 4 bulan adalah 100 hari. Maka kita cari tingkat penggunaan bahan baku per hari.

$$
\begin{aligned}
& d=\frac{D}{t} \\
& d=\frac{187.005}{100}
\end{aligned}
$$




$$
d=1.757 .61=187,5
$$

Maka Re-Order Point nya adalah sebagai berikut :

$$
\begin{aligned}
\text { ROP } & =\quad \mathrm{D} \times \mathrm{L} \\
& =\quad 187.005 \times 14 \text { hari } \\
& =2,618,07=2,618 \mathrm{Kg}
\end{aligned}
$$

Jadi pihak perusahaan harus melakukan pemesanan ketika jumlah bahan baku sebesar 2,618 $\mathrm{kg}$.

\section{Perbandingan Kebijakan Perusahaan dengan Metode EOQ tahun 2019}

\begin{tabular}{clcc} 
No & \multicolumn{1}{c}{ Keterangan } & Kebijakan Perusahaan & Metode EOQ \\
1 & Pembelian rata-rata bahan baku & $46.761 \mathrm{Kg}$ & $127.607 \mathrm{Kg}$ \\
2 & Total Biaya Persediaan & Rp. 2.286.376,58 & Rp. 812.009 \\
3 & Frekuensi Pemesanan & 4 & 1 \\
4 & Safety Stock & - & $1.095 \mathrm{Kg}$ \\
5 & Re-Order Point & - & $2.618 \mathrm{Kg}$
\end{tabular}

\section{Sumber : Data PT. NCI yang di olah.}

Berikut adalah hasil kebijakan perusahaan dan dengan metode EOQ dalam bentuk grafik.

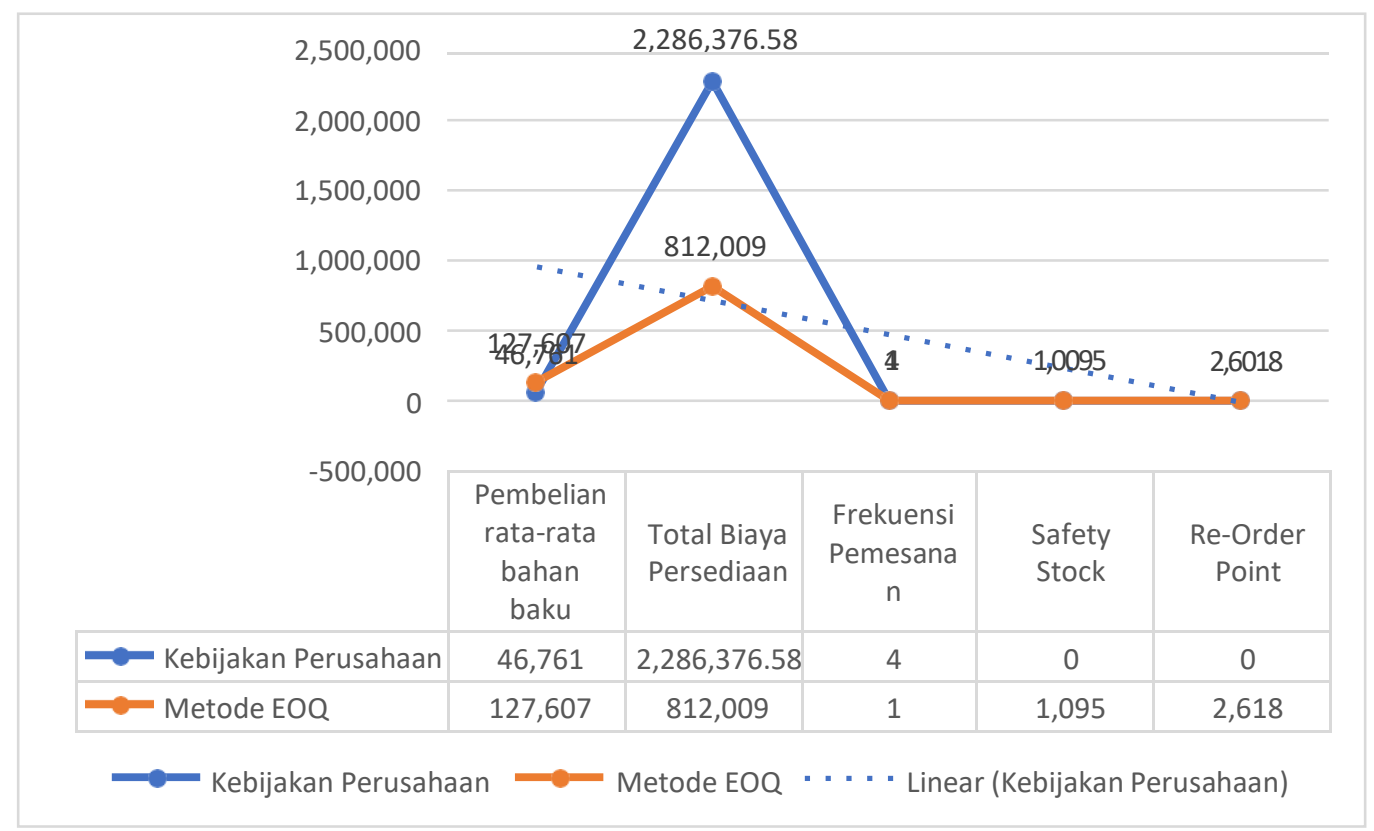




\section{KESIMPULAN}

1. Hasil perhitungan menggunakan $\mathrm{ABC}$ Analysis di dapatkan hasil bahwa material HN-10 NH167L berada di kelas A dengan persentase $64,20 \%$ dari total kebutuhan bahan baku.

2. Frekuensi pembeliaan bahan baku PT. NCI untuk material HN-10 Nh-167L dari bulan September 2019 sampai dengan Desember 2019 dengan metode EOQ adalah 1 kali pemesanan dalam satu periode (1 tahun), sedangkan kebijakan perusahaan 4 kali.

3. Total biaya persediaan bahan baku perusahaan bila dihitung menurut EOQ adalah sebesar Rp. 812.009 sedangkan kebijakan perusahaan sebesar Rp. Rp. 2.286.376,58. Penghematan biaya bila menggunakan metode EOQ adalah sebesar Rp. 1.474.367,58

4. PT. NCI tidak menetapkan adanya persediaan pengaman dalam kebijakannya, sedangkan dalam metode EOQ, perusahaan harus mengadakan persediaan pengaman untuk memperlancar proses produksi dengan jumlah $1.095 \mathrm{Kg}$, untuk mengantisipasi keterlambatan pengiriman bahan baku perusahaan harus melakukan pemesanan bahan baku kembali saat persediaan bahan baku berada pada waktu jumlah sebesar $2.618 \mathrm{Kg}$.

\section{DAFTAR PUSTAKA}

Afianti, H. F., \& Azwir, H. H. (2017). Pengendalian Persediaan Dan Penjadwalan Pasokan Bahan Baku Import Dengan Metode Abc Analysis Di Pt Unilever Indonesia, Cikarang, Jawa Barat. Jurnal Iptek, 21(2), 77-90.

Amrillah, A. F., Zahroh, Z. A., \& Wi Endang NP, M. G. (2016). Analisis metode economic order quantity (eoq) sebagai dasar pengendalian persediaan bahan baku pembantu (studi pada PG. Ngadirejo Kediri-PT. Perkebunan Nusantara X). Jurnal Administrasi Bisnis, 33(1), 35-42.

Damodar., Gujarati. 2018. linear regression: a mathematical introduction.

Gema, L., Retno, S. 2014. Analisis Pengendalian Persediaan Bahan Baku Daginig dan Ayam dengan Menggunakan Metode Economic Order Quantity (EOQ) Pada Restoran Steak Ranjang. Bandung : 2-3

Happy, F., \& Hery,H. 2016 Pengendalian Persediaan Dan Penjadwalan Pasokan Bahan Baku Impor Dengan Metode Abc Analysis Di Pt Unilever Indonesia, Cikarang, Jawa Barat.

Safa'at. 2016. Pengendalian Persediaan Bahan Baku Dengan Metode EOQ (Economic Order Quantity) Untuk Menentukan Jumlah Purchase Order (PO) Pada PT. Varia Usaha Beton, Plant Beton Siap Pakai Gresik. Surabaya.

Setiawan, Jandu, 2010. Pengendalian Bahan Baku dengan Metode Analisis ABC pada Pt. Soelystyowaty Kusuma Tekstile Sragen. 2010. 